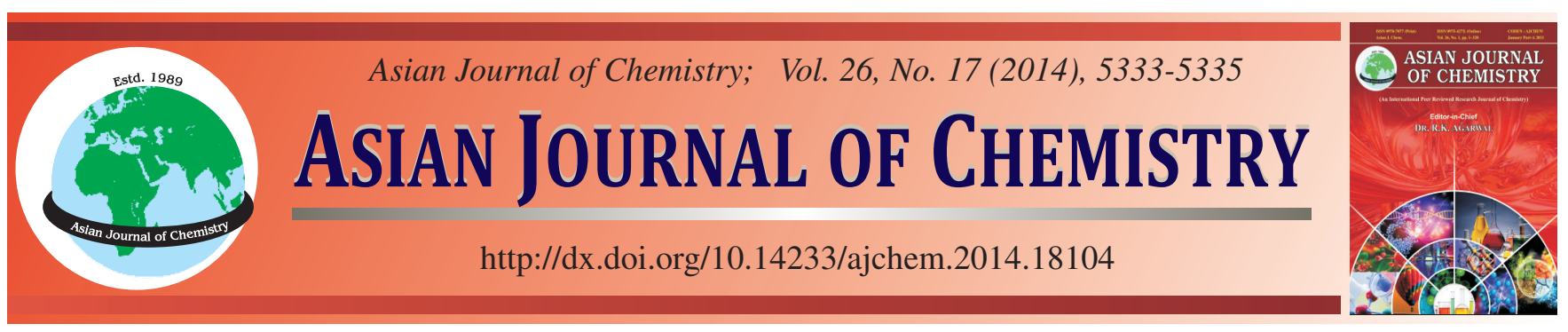

\title{
Effect of Sintering Temperature on Electrical Conductivity, Hardness and Friction Properties of $\mathrm{Cu} / \mathrm{MgB}_{2}$ Composites $\dagger$
}

\begin{abstract}
QING YANG $^{1,2, *}$, JinYANG HuANG ${ }^{1}$, JUNTAO Zou ${ }^{1,2}$ and Huitan Fu ${ }^{3}$
${ }^{1}$ Faculty of Material Science and Engineering, Xi'an University of Technology, 5 South Jinhua Road, Xi'an 710048, P.R. China

${ }^{2}$ Shaanxi Province Key Laboratory for Electrical Materials and Infiltration Technology, Xi'an University of Technology, 5 South Jinhua Road, Xi'an 710048, P.R. China

${ }^{3}$ School of Material Science and Engineering, Henan University of Technology, 195 West Zhongyuan Road, Zhengzhou 450007, P.R. China

*Corresponding author: Tel./Fax: +86 29 82312185; E-mail: yangqing@ xaut.edu.cn

The $\mathrm{Cu} / \mathrm{MgB}_{2}$ composites with $\mathrm{MgB}_{2}$ content of $10,20,30$ vol. \% were fabricated by pressing-sintering at $800{ }^{\circ} \mathrm{C}$ and repressingresintering at $900^{\circ} \mathrm{C}$. The effect of sintering temperature on the properties of $\mathrm{Cu} / \mathrm{MgB}_{2}$ composites including the relative density, hardness, friction coefficient and electrical conductivity was investigated. The results showed that the decrease of sintering temperature from 900 to $800{ }^{\circ} \mathrm{C}$ contributed to the increase of relative density and hardness of $\mathrm{Cu} / \mathrm{MgB}_{2}$ composites with $\mathrm{MgB}_{2}$ content lower than 30 vol. \% and contributed to the increase of friction coefficient and electrical conductively of $\mathrm{Cu}-20 \% \mathrm{MgB}_{2}$ composite. The properties of $\mathrm{Cu} / \mathrm{MgB}{ }_{2}$ composites sintered at $800{ }^{\circ} \mathrm{C}$, which were lower than those sintered at $900{ }^{\circ} \mathrm{C}$, were increased and approximated to those sintered at $900{ }^{\circ} \mathrm{C}$ after the repressing-resintering process.
\end{abstract}

Keywords: $\mathrm{Cu} / \mathrm{MgB}_{2}$ composite, Vacuum sintering, Resintering, Sintering temperature.

ᄂ - - - - - - - - - - - - - - - - - - - - - - - - -

\section{INTRODUCTION}

Copper is used in a wide variety of commercial applications due to its high electrical and thermal conductivity. The copper matrix composites reinforced by various ceramics such as oxides, carbides and borides have been investigated to improve their mechanical properties ${ }^{1-3}$. On the other hand, $\mathrm{MgB}_{2}$ has been widely investigated as a high-temperature superconductor since it was discovered in $2001^{4,5}$, such as the effect of copper addition on the superconducting property of $\mathrm{MgB}_{2}{ }^{6-8}$. In addition, $\mathrm{MgB}_{2}$ shows particular interest for the photoinduced non-linear optics used for the shift of the phase transitions ${ }^{9}$. However, $\mathrm{MgB}_{2}$ may serve as a candidate for reinforcement of copper matrix due to its excellent properties such as low density, low electrical resistivity, low linear thermal expansion coefficient and high mechanical properties ${ }^{10-12}$.

Previously, Liu et al. ${ }^{12}$ reported the preparation of $\mathrm{Cu} / \mathrm{MgB}_{2}$ composites by reaction sintering of $\mathrm{Cu}-\mathrm{Mg}-\mathrm{B}$ system. We reported the fabrication of $\mathrm{Cu} / \mathrm{MgB}_{2}$ composites by vacuum sintering of copper and $\mathrm{MgB}_{2}{ }^{13}$. However, the effect of fabrication process in particular the sintering temperature on the properties of $\mathrm{Cu} / \mathrm{MgB}_{2}$ composites is still not clear. Therefore, the effect of sintering temperature on the electrical conductivity, hardness and friction properties is investigated in this research.

\section{EXPERIMENTAL}

The copper powders (270 mesh) mixed with 10, 20, 30 vol. $\% \mathrm{MgB}_{2}$ powders (200 mesh) were used as the starting materials. The $\mathrm{Cu} / \mathrm{MgB}_{2}$ composites were fabricated by pressing-sintering at 800 and $900{ }^{\circ} \mathrm{C}$ for $2 \mathrm{~h}$, respectively and then by repressing-resintering at $900{ }^{\circ} \mathrm{C}$ for $2 \mathrm{~h}$. The density was measured based on Archimedes drainage method. The hardness was evaluated by Brinell hardness tester. The friction test was performed on a friction tester in a pin-on-disc contact configuration under dry condition at room temperature in air. The applied load was $100 \mathrm{~N}$, the rotation speed was $200 \mathrm{rpm}$, the counterpart material was 45 steel and the test time was $1800 \mathrm{~s}$. The electrical conductivity was evaluated by eddy current electrical conductivity tester.

\section{RESULTS AND DISCUSSION}

Fig. 1 shows the variation of relative density of $\mathrm{Cu} / \mathrm{MgB}_{2}$ composites with $\mathrm{MgB}_{2}$ content. When the $\mathrm{MgB}_{2}$ content is 


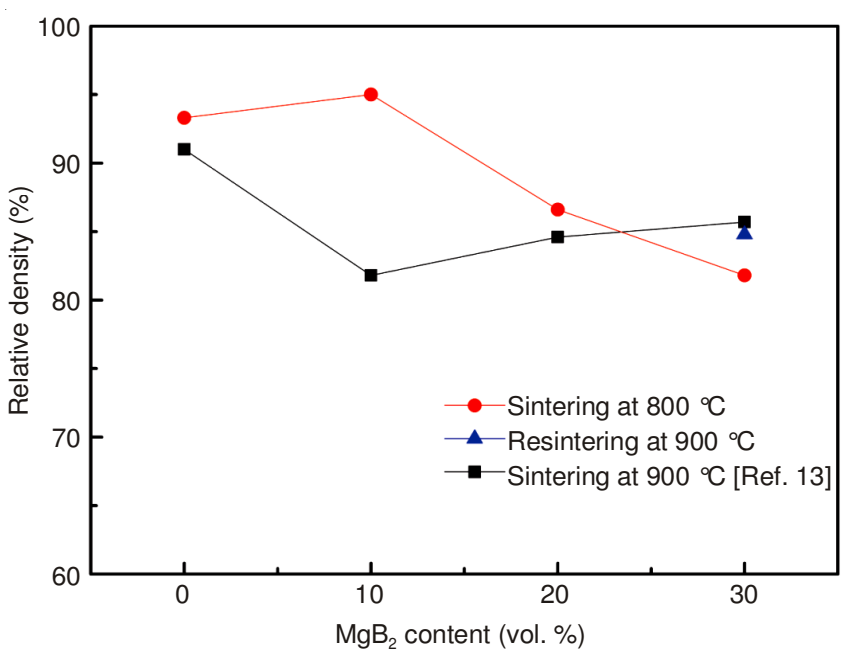

Fig. 1. Variation of relative density of $\mathrm{Cu} / \mathrm{MgB}_{2}$ composites with $\mathrm{MgB}_{2}$ content

lower than 30 vol. $\%$, the relative density of $\mathrm{Cu} / \mathrm{MgB}_{2}$ composites sintered at $800{ }^{\circ} \mathrm{C}$ is higher than that sintered at $900{ }^{\circ} \mathrm{C}$. In particular, the relative density of $\mathrm{Cu}-10 \% \mathrm{MgB}_{2}$ composite is increased by $16.1 \%$. The relative density of $\mathrm{Cu}-30 \% \mathrm{MgB}_{2}$ composite sintered at $800{ }^{\circ} \mathrm{C}$ is increased after repressingresintering at $900{ }^{\circ} \mathrm{C}$ and becomes slightly lower than that sintered at $900{ }^{\circ} \mathrm{C}$.

Fig. 2 shows the variation of hardness of $\mathrm{Cu} / \mathrm{MgB}_{2}$ composites with $\mathrm{MgB}_{2}$ content. When the $\mathrm{MgB}_{2}$ content is lower than 30 vol. $\%$, the hardness of $\mathrm{Cu} / \mathrm{MgB}_{2}$ composites sintered at $800{ }^{\circ} \mathrm{C}$ is higher than that sintered at $900{ }^{\circ} \mathrm{C}$. The hardness of $\mathrm{Cu}-10 \% \mathrm{MgB}_{2}$ composite is particularly increased by $48.4 \%$. The hardness of $\mathrm{Cu}-30 \% \mathrm{MgB}_{2}$ composite sintered at $800{ }^{\circ} \mathrm{C}$ is increased after repressing-resintering at $900{ }^{\circ} \mathrm{C}$ and becomes slightly higher than that sintered at $900{ }^{\circ} \mathrm{C}$.

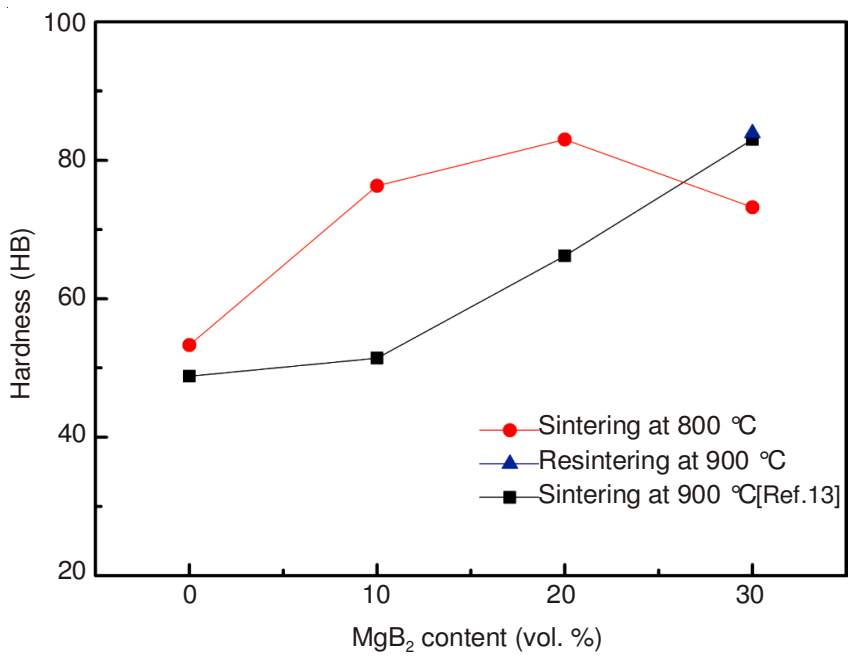

Fig. 2. Variation of hardness of $\mathrm{Cu} / \mathrm{MgB}_{2}$ composites with $\mathrm{MgB}_{2}$ content

Fig. 3 shows the variation of average friction coefficient of $\mathrm{Cu} / \mathrm{MgB}_{2}$ composites with $\mathrm{MgB}_{2}$ content. The average friction coefficient of $\mathrm{Cu}-20 \% \mathrm{MgB}_{2}$ composite sintered at $800{ }^{\circ} \mathrm{C}$ is $1.5 \%$ higher than that sintered at $900^{\circ} \mathrm{C}$. In addition, the average friction coefficient of $\mathrm{Cu}-10 \% \mathrm{MgB}_{2}$ and $\mathrm{Cu}-30 \%$ $\mathrm{MgB}_{2}$ composites sintered at $800{ }^{\circ} \mathrm{C}$ is increased after repressing-resintering at $900^{\circ} \mathrm{C}$. The average friction coefficient of

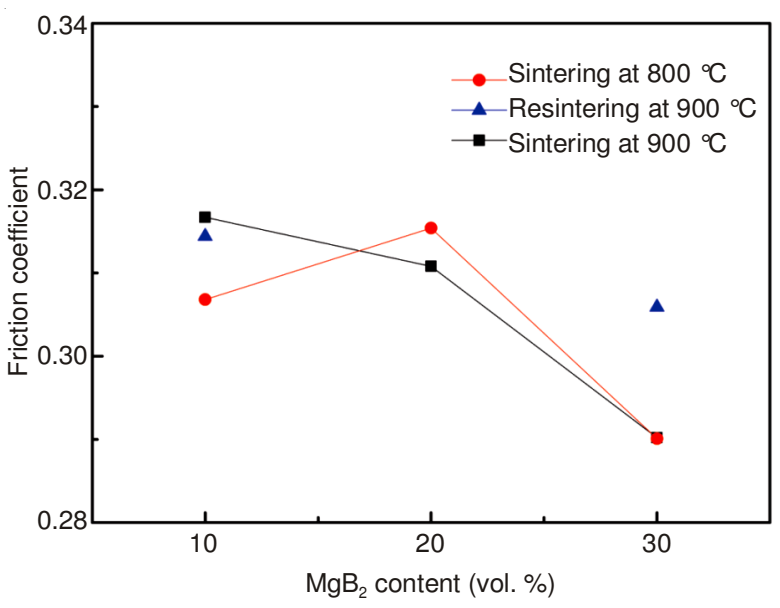

Fig. 3. Variation of average friction coefficient of $\mathrm{Cu} / \mathrm{MgB}_{2}$ composites with $\mathrm{MgB}_{2}$ content

resintered $\mathrm{Cu}-10 \% \mathrm{MgB}_{2}$ composite is slightly lower than that sintered at $900{ }^{\circ} \mathrm{C}$ and the average friction coefficient of resintered $\mathrm{Cu}-30 \% \mathrm{MgB}_{2}$ composite is $5.4 \%$ higher than that sintered at $900{ }^{\circ} \mathrm{C}$.

Fig. 4 shows the variation of electrical conductivity of $\mathrm{Cu} / \mathrm{MgB}_{2}$ composites with $\mathrm{MgB}_{2}$ content. The electrical conductivity of $\mathrm{Cu}-20 \% \mathrm{MgB}_{2}$ composite sintered at $800{ }^{\circ} \mathrm{C}$ is $11.9 \%$ higher than that sintered at $900{ }^{\circ} \mathrm{C}$. In addition, the electrical conductivity of $\mathrm{Cu}-10 \% \mathrm{MgB}_{2}$ and $\mathrm{Cu}-30 \% \mathrm{MgB}_{2}$ composites sintered at $800{ }^{\circ} \mathrm{C}$ is increased after repressingresintering at $900{ }^{\circ} \mathrm{C}$ and becomes slightly higher than that sintered at $900{ }^{\circ} \mathrm{C}$.

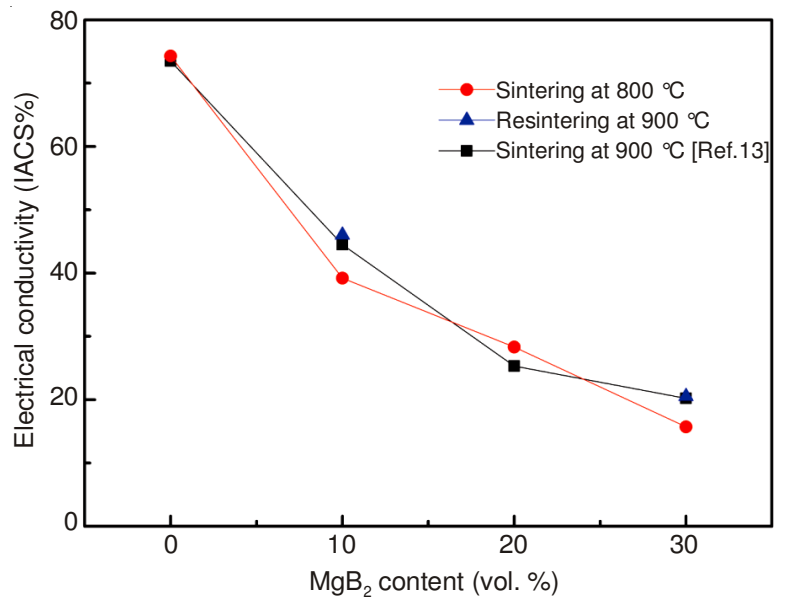

Fig. 4. Variation of electrical conductivity of $\mathrm{Cu} / \mathrm{MgB}_{2}$ composites with $\mathrm{MgB}_{2}$ content

By comparing the properties of $\mathrm{Cu} / \mathrm{MgB}_{2}$ composites sintered at 800 and $900^{\circ} \mathrm{C}$, it was found that the relative density, hardness, friction coefficient and electrical conductivity of $\mathrm{Cu} / \mathrm{MgB}_{2}$ composites varied with the sintering temperature. The decrease of sintering temperature from 900 to $800{ }^{\circ} \mathrm{C}$ contributed to the increase of relative density and hardness of $\mathrm{Cu} / \mathrm{MgB}_{2}$ composites with $\mathrm{MgB}_{2}$ content lower than 30 vol. \% and contributed to the increase of friction coefficient and electrical conductively of $\mathrm{Cu}-20 \% \mathrm{MgB}_{2}$ composite. On the other hand, it was found that the relative density and hardness of $\mathrm{Cu}-30 \% \mathrm{MgB}_{2}$ composite sintered at $800{ }^{\circ} \mathrm{C}$ and the friction coefficient and electrical conductively of $\mathrm{Cu}-10 \% \mathrm{MgB}_{2}$ and 
$\mathrm{Cu}-30 \% \mathrm{MgB}_{2}$ composites sintered at $800^{\circ} \mathrm{C}$ could be increased after the repressing-resintering process, which approximated to that sintered at $900{ }^{\circ} \mathrm{C}$.

It is generally accepted that the sintering temperature is a controlling factor in sintering mechanism ${ }^{14}$. However, the different effect of sintering temperature on the properties of ceramic reinforced metal matrix composites has been reported $^{2,14-16}$. At higher sintering temperature, a denser structure could be obtained due to the higher diffusion rate, which then resulted in the higher hardness ${ }^{14-16}$. In addition, the higher sintering temperature may cause the formation of a small amount of oxidation, resulting in the lower density and lower electrical conductivity ${ }^{2}$. On the other hand, the grain growth may occur at higher sintering temperature, which would result in the lower hardness ${ }^{2,15}$. Although the effect of sintering temperature on the electrical conductivity of $\mathrm{Cu} / \mathrm{MgB}_{2}$ composites was observed, the electrical conductivity still showed a declining trend with the increase of $\mathrm{MgB}_{2}$ content, which can be attributed to the increase in the electron-photon scattering and decrease in the mean free path of electrons and photons due to the increased interface of $\mathrm{Cu}-\mathrm{MgB}_{2}$. Therefore, the properties of as-sintered $\mathrm{Cu} / \mathrm{MgB}_{2}$ composites are a complex function of the sintering temperature and $\mathrm{MgB}_{2}$ content. ${ }^{16}$ In this work, the experimental results revealed that the difference of $100^{\circ} \mathrm{C}$ in the sintering temperature is important to improve the properties of $\mathrm{Cu} / \mathrm{MgB}_{2}$ composites. In addition, it was suggested that the higher properties could be obtained by pressing-sintering at $800{ }^{\circ} \mathrm{C}$ or combining with repressingresintering at $900{ }^{\circ} \mathrm{C}$ rather than simply by pressing-sintering at $900{ }^{\circ} \mathrm{C}$.

\section{Conclusion}

The $\mathrm{Cu} / \mathrm{MgB}_{2}$ composites with $\mathrm{MgB}_{2}$ content of 10,20 , 30 vol. \% were fabricated by pressing-sintering at $800{ }^{\circ} \mathrm{C}$ and repressing-resintering at $900{ }^{\circ} \mathrm{C}$ and the properties including relative density, hardness, friction coefficient and electrical conductivity were compared with that sintered at $900{ }^{\circ} \mathrm{C}$. The decrease of sintering temperature contributed to the increase of relative density and hardness of $\mathrm{Cu} / \mathrm{MgB}_{2}$ composites with $\mathrm{MgB}_{2}$ content lower than $30 \mathrm{vol}$. \% and contributed to the increase of friction coefficient and electrical conductively of $\mathrm{Cu}-20 \% \mathrm{MgB}_{2}$ composite by 1.5 and $11.9 \%$, respectively. In particular, the relative density and hardness of $\mathrm{Cu}-10 \% \mathrm{MgB}_{2}$ composite were increased by 16.1 and $48.4 \%$, respectively. On the other hand, the relative density and hardness of resintered $\mathrm{Cu}-30 \% \mathrm{MgB}_{2}$ composite was increased and approximated to that sintered at $900{ }^{\circ} \mathrm{C}$. The average friction coefficient of resintered $\mathrm{Cu}-10 \% \mathrm{MgB}_{2}$ composite was increased and approximated to that sintered at $900^{\circ} \mathrm{C}$ and the average friction coefficient of resintered $\mathrm{Cu}-30 \% \mathrm{MgB}_{2}$ composite was $5.4 \%$ higher than that sintered at $900{ }^{\circ} \mathrm{C}$. The electrical conductivity of resintered $\mathrm{Cu}-10 \% \mathrm{MgB}_{2}$ and $\mathrm{Cu}-30 \% \mathrm{MgB}_{2}$ composites was increased and approximated to that sintered at $900{ }^{\circ} \mathrm{C}$.

\section{ACKNOWLEDGEMENTS}

A part of this work is supported by China Postdoctoral Science Foundation Funded Project (No. 2013M532071) and Shaanxi Provincial Project of Special Foundation of Key Disciplines, China.

\section{REFERENCES}

1. K. Dash, B.C. Ray and D. Chaira, J. Alloys Comp., 516, 78 (2012).

2. G. Celebi Efe, T. Yener, I. Altinsoy, M. Ipek, S. Zeytin and C. Bindal, J. Alloys Comp., 509, 6036 (2011).

3. J.S. Kim, D.V. Dudina, J.C. Kim, Y.S. Kwon, J.J. Park and C.K. Rhee, J. Nanosci. Nanotechnol., 10, 252 (2010).

4. J. Nagamatsu, N. Nakagawa, T. Muranaka, Y. Zenitani and J. Akimitsu, Nature, 410, 63 (2001).

5. P.C. Caneld, S.L. Bud'ko and D.K. Finnemore, Physica C, 385, 1 (2003).

6. M.A. Aksan, A. Guldeste, Y. Balci and M.E. Yakinci, Solid State Commun., 137, 320 (2006).

7. Z.Q. Ma, Y.C. Liu, Q.Z. Shi, Q. Zhao and Z.M. Gao, Supercond. Sci. Technol., 21, 065004 (2008).

8. Y. Tang, X. Kong and J. Zang, Physica C, 469, 1902 (2009).

9. N.S. AlZayed, I.V. Kityk, S. Soltan, A. Wojciechowski, A.O. Fedorchuk, G. Lakshminarayana and M. Shahabuddin, J. Alloys Comp., 594, 60 (2014).

10. P.C. Canfield, D.K. Finnemore, S.L. Bud'ko, J.E. Ostenson, G. Lapertot, C.E. Cunningham and C. Petrovic, Phys. Rev. Lett., 86, 2423 (2001).

11. W. Goldacker, S.I. Schlachter, S. Zimmer and H. Reiner, Supercond. Sci. Technol., 14, 787 (2001).

12. D.B. Liu, M.F. Chen, A. Rauf, C.X. Cui and J.J. Tan, J. Alloys Comp., 466, 87 (2008).

13. Q. Yang, J. Zou, Z. Liu and X. Yu, Mater. Sci. Forum, 749, 141 (2013).

14. M. Rahimian, N. Ehsani, N. Parvin and H.R. Baharvandi, Mater. Des., 30, 3333 (2009).

15. M. Rahimian, N. Ehsani, N. Parvin and H.R. Baharvandi, J. Mater. Process. Technol., 209, 5387 (2009).

16. B. Leszczynska-Madej, Arch. Metall. Mater, 58, 43 (2013). 